\title{
Trayectorias de vida e inserción política de los médicos en Buenos Aires, 1820-1870
}

Lifelines and political insert of physicians in Buenos Aires, 1820-1870

Mariano Di Pasquale

CONICET/Instituto de Estudios Históricos - Universidad Nacional de Tres de Febrero, Argentina mariano.dipasquale@gmail.com

\section{Resumen:}

Este artículo se propone reponer y analizar las trayectorias de vida de ciertos médicos para realizar una primera aproximación en torno a las formas de su participación política en Buenos Aires entre 1820 y 1870 . Teniendo presente este objetivo se desea contribuir en una doble dimensión. Por un lado, al contrario de lo que ha sostenido cierta historiografía tradicional, se da cuenta que los cruces entre el mundo de la medicina y el de la política pueden ubicarse en una cronología anterior; por el otro, se busca mostrar la complejidad y la diversidad de situaciones que experimentaron los médicos en relación con espacio político y sus distintas modalidades de acceso al poder. Es probable que estas experiencias y prácticas políticas acumuladas a lo largo de la primera mitad del siglo XIX, combinada con el ejercicio profesional, constituya un punto de referencia importante para comprender cómo algunos médicos y, con ellos también, un discurso-saber médico obtenga una fuerte presencia en la toma de decisiones en el Estado-nacional argentino a partir de 1880 .

Palabras Clave: Trayectorias de vida, Inserción política, Médicos, Buenos Aires, Siglo XIX.

\section{Abstract:}

This article proposes to analyze the trajectories of life of certain doctors to make a first approximation around the forms of their political participation in Buenos Aires between 1820 and 1870. With this objective in mind we wish to contribute in a double dimension. On the one hand, contrary to what some traditional historiography has maintained, it seems to us that these crosses can be detected in an earlier chronology; on the other, it seeks to show the complexity and diversity of situations experienced by doctors in relation to political power. It is likely that these experiences and political practices accumulated throughout the first half of the nineteenth century, combined with professional practice, constitute an important point of reference for understanding how some doctors and, with them, also a medical discourse, obtain a strong presence in decision making in the Argentine nationalstate from 1880 .

KEYWORDS: Lifelines, Political integration, Physicians, Buenos Aires, 19th century.

\section{INTRODUCCIÓN}

Durante el período escogido los médicos "diplomados" que habitaron Buenos Aires asumieron distintas y variadas funciones tales como ejercer y practicar su profesión en un hospital o de forma particular, impartir clases en las cátedras de la Universidad, integrar tropas y ejércitos, impulsar debates sobre temas académicos en la prensa, vacunar a la población, controlar y administrar el ejercicio profesional a través de instituciones específicas como el Tribunal de Medicina o la Academia de Medicina, inspeccionar la sanidad del puerto y la salud de la población carcelaria, entre tantas otras tareas.

La variedad de actividades en las cuales los médicos están involucrados, por cierto médicos de distintas edades y procedencias, nos sugieren que éstos tuvieron una vida activa en el Buenos Aires de la primera mitad del siglo XIX. En paralelo, podríamos agregar que ese saber-poder médico se encontraba en plena formación e intentaba fijar los límites y los controles disciplinares de un ejercicio profesional que consistía en velar y a 
atender la salud de la población. Estos factores, sumados a otros, como la necesidad de conseguir empleos, seguramente estimularon a los médicos a ponerse en contacto frecuente con diversos actores sociales entre los cuales los grupos gobernantes figuraron en primer lugar.

$\mathrm{Al}$ contrario de lo que ha sostenido cierta historiografía tradicional nos parece que los cruces entre medicina y política pueden detectarse en una cronología anterior. En principio, cabe aclarar que existieron antecedentes en la relación médico-poder político que pueden ubicarse entre el período tardo-colonial y la primera década de 1810. La participación de Cosme Mariano Argerich, Juan Madera y Justo García Valdés en el Cabildo abierto del 22 de mayo de 1810; el manejo concentrado de atribuciones de Cristóbal de Montufar en el Instituto Médico Militar y su vinculación con el Directorio; las conexiones y el apoyo de la mayoría de los miembros de la Academia de Medicina al grupo rivadaviano, por mencionar algunos casos, que evidencian estas primeras conexiones. Evidentemente, el proceso de construcción de la profesión médica se mezcló constantemente ya tempranamente respecto de los vaivenes de las distintas administraciones, los cambios institucionales, los problemas económicos, las guerras y el faccionalismo político.

Retomando los aportes provenientes de trabajos más actuales como los de María Silvia Di Liscia (2002) y los de Leandro González Leandri (1999; 2005 y 2006), este artículo propone analizar las trayectorias de vida de ciertos médicos en el espacio porteño para realizar una primera aproximación en torno a las formas de acceso y participación política entre 1820 y 1870.

Esta propuesta parte de la reconstrucción y análisis de las trayectorias de vida de ciertos médicos representativos. Esto significa recuperar y poner en consideración los aspectos biográficos, los espacios y los "momentos" de formación, el universo laboral, la esfera privada, los episodios y acontecimientos "claves" de las historias vividas y experiencias personales, los viajes e intercambios culturales, las tramas de amigos, colaboradores, discípulos, estudiantes, entre otros elementos que nos parecen centrales a la hora de emprender este nivel de análisis. Se coincide con Pierre Rosanvallon, cuando señala que es necesario recurrir cada vez más a la historia individual de los sujetos, a sus familias, redes, trayectorias y a los procesos que los afectaron (Fitoussi y Rosanvallon, 1997). Consideramos que en lugar de anclarse en miradas generales, aplicables a todos los casos, resulta imprescindible desarrollar la capacidad para construir abordajes singulares ante situaciones que son singulares, ubicadas en el marco de procesos sociales, políticos y culturales en los que comparten condiciones de vida (Di Pasquale y Summo, 2015, 12).

En estos repertorios de acciones es que identificamos una serie de estrategias de ingreso y participación que podríamos clasificar en tres momentos clave. En la década de 1820 y hasta los primeros años de la siguiente, se advierte una presencia de médicos que acceden a la práctica política en el marco del poder legislativo provincial. En esta etapa varios médicos fueron elegidos diputados de la Sala de Representantes de Buenos Aires participando en importantes debates parlamentarios. Posteriormente, a partir del segundo gobierno de Rosas, si bien se produce un alejamiento de los médicos del espacio deliberativo, éstos no dejaron de estar ausentes desarrollando otras estrategias de intervención política, por cierto, más informales. Las modalidades de participación política de los médicos fueron variadas: desde generar habilidades para estrechar acercamientos y vínculos con los "hombres de poder"; re-posicionarse a partir del crédito profesional y/o en su prestigio científico adquirido; en caso de no adherir con la propuesta de Rosas, montar maniobras de simulación, declararse en oposición abierta y participar en levantamientos militares, optar por acciones de índole más silenciosa o clandestina y/o, ocuparse de ejercer duras críticas y formar alianzas desde el exilio. Luego de 1852 hasta 1870, encontramos una etapa en donde los médicos que actuaron en el período anterior se lanzaron a participar de la política pero esta vez (otra vez) no sólo mediante la obtención de cargos en los cuerpos legislativos sino incluso alcanzando puestos en el Ejecutivo nacional.

Teniendo presente este proceso deseamos contribuir a mostrar la complejidad y la diversidad de situaciones que experimentaron los médicos en relación con el poder político. Por otro lado, es probable que esta acumulación de experiencias y prácticas políticas desarrolladas a lo largo de la primera mitad del siglo XIX, combinada con el ejercicio profesional, constituya un punto de referencia para comprender mejor cómo los 
médicos y, con ellos, el discurso médico, obtienen una fuerte presencia en la toma de decisiones en el Estadonacional a partir de 1880 .

\section{LOS MÉdicos COMO "REPRESENTANTES DEL PUEBLO": PRIMERAS TRAYECTORIAS E INTERVENCIONES EN LA VIDA POLÍTICA}

Es conveniente comenzar este apartado con una aclaración. Resulta importante distinguir entre los nombramientos de médicos por los sucesivos gobiernos independientes en cargos en el ejército (o las milicias) y en las instituciones relacionadas con la profesión tales como la Universidad, el Tribunal de Medicina, la Academia de Medicina, Vacunador, Hospitales, Médico de Policía, etc....que son oficios públicos de aquellos cargos ejercidos dentro de un espacio político propiamente dicho y obtenidos a través del diseño representativo que se abrió con la ley electoral de 1821 en la provincia de Buenos Aires.

En general estos últimos puestos estuvieron relacionados con el poder legislativo: varios médicos fueron elegidos en calidad de diputados de la Sala de Representantes de Buenos Aires. Los "médicos diplomados" que actuaron como políticos en este período, podríamos decir, fueron también "médicos legisladores”. El prestigio social, las conexiones políticas dadas por el ejercicio profesional, la creciente importancia de la medicina en la salud poblacional, hicieron que los médicos fueran personajes representativos en sus respectivas jurisdicciones y fueran elegidos en las candidaturas que armaban los grupos políticos en un régimen de "competencia internotabiliar" como explica Marcela Ternavasio (2002, pp. 45-60). Por otra parte, Noemí Goldman (2000 y 2003) señala que la provincia de Buenos Aires reguló el funcionamiento de sus instituciones por medio de leyes dictadas entre 1821 y 1824 y prácticas no formalizadas que se erigieron en principios constitutivos del nuevo régimen político. Por ello, la Sala de Representantes ocupó un central el lugar en la escena política bonaerense. Esta institución abrió la posibilidad de introducir prácticas políticas republicanas más precisas como considerar al juego político dentro del marco de la deliberación que ejerce un poder colegiado y comprender que éste actúa como potencial canal en la resolución de conflictos.

Bajo la gestión del gobernador Martín Rodríguez surgió un inusitado diseño del espacio público: el modelo republicano y representativo de gobierno asentado en nuevos mecanismos institucionales. En la provincia de Buenos Aires no se dictó constitución (a diferencia del resto de las provincias) pero sí se consolidó informalmente un sistema de poder legislativo y un mecanismo de elección del mismo. En 1821 se dictó la ley electoral y el derecho al voto "universal" que incorporaba a la campaña bonaerense. El derecho al sufragio junto a un régimen de elección directa de diputados a la Sala de Representantes - poder legislativo provincial creado en 1820 y encargado de designar al gobernador- causó una nueva concepción de la relación entre gobernantes y gobernados (Ternavasio 2002, pp. 40-60).

Paralelamente que se iba conformando el régimen político, Bernardino Rivadavia, ministro de gobierno de Martín Rodríguez, implementó un abanico de reformas en el ámbito político, institucional, económico, eclesiástico, educativo, cultural y militar (Ternavasio 1998, pp. 161-197). El objetivo de estas reformas en su conjunto era terminar drásticamente con la herencia de la estructura colonial y "modernizar" las prácticas y el imaginario político. Es decir, establecer una nueva cultura política afín a las nuevas concepciones ilustradas y liberales de la época. Este plan reformista también buscó conformar un tipo de ciudadano basado en una matriz "republicana-ilustrada" en consonancia con el nuevo orden político. Se alentaba la formación de una generación de hommes de lettrés que debían comportarse y reconocerse a sí mismos en calidad de "ciudadanos".

En cuanto a la cultura científica es pertinente señalar que entre 1821 y 1823 se crearon nuevas instituciones que estimularon el intercambio científico y profesional: la Universidad de Buenos Aires y la Academia de Medicina. Asimismo, se creó la Sociedad Literaria y la Sociedad de Ciencias Físico-Matemáticas, asociaciones que también tuvieron un papel importante en la divulgación científica. Aparece, pues, un intento de institucionalización a través de las reformas rivadavianas, inspiradas en las doctrinas de la Ilustración tardía 
y en la práctica de un Estado provincial confiado en su capacidad y en su derecho de incidir sobre todas las facetas de la vida social (Myers 1998, p. 386).

El 9 de agosto de 1821 firmó junto al gobernador el Edicto de erección de la Universidad de Buenos Aires (Gutiérrez, 1998, p. 333). La estructura departamental del nuevo organismo se realizó agrupando distintas instituciones heredadas de la época colonial organizándose sobre la base de instituciones preexistentes, como el Instituto Médico Militar, los restos de la Academia de Matemáticas y la Escuela de Dibujo de fray Francisco de Paula Castañeda. Pero también se introdujeron modificaciones importantes como la inclusión de nuevas cátedras y docentes. Las reformas más importantes ocurrieron en el Departamento de Estudios Preparatorios, donde se crearon nuevas cátedras, como la de Química Experimental a cargo de Manuel Moreno (abril de 1822 hasta marzo de 1828), la de Física Experimental, a cargo del médico italiano Pedro Carta Molina (abril de 1826 hasta noviembre de 1827) y la de Ideología, a cargo del profesor Juan Manuel Fernández de Agüero (marzo de 1822 hasta diciembre de 1823).

La llegada a Buenos Aires de un gabinete de física, un laboratorio de química, calcos de anatomía y material para preparaciones zoológicas comprados por Rivadavia a la casa Baillot, Piet \& Cie., de Paris, por intermedio de los banqueros Hullet Brothers \& Co., de Londres, que actuaban como agentes consulares, fue sin duda un acontecimiento significativo para la enseñanza científica. Estos equipos, que llegaron en dos remesas, fueron instalados en el Convento de Santo Domingo y puestos a cargo de Carlos Ferraris (1792-1859) (Gutiérrez, 1998, p. 342).

Asimismo cabe recordar que Rivadavia contrató, directa o indirectamente, varios profesores de ciencias para el Río de la Plata, ya sea durante alguna de sus largas estadías en Europa (entre 1814 y 1820 y entre 1824 y 1826) o a través de agentes consulares. Así llegaron el español Felipe Senillosa, el mexicano José de Lanz, el médico italiano Pedro Carta Molina y su amigo el boticario Carlos Ferraris. El más prestigioso, sin duda, fue el naturalista francés Aimé Bonpland. También, Ottaviano F. Mossotti, que llegó una década más tarde, fue contratado durante la presidencia de Rivadavia (De Asúa, 2010, 174).

En este contexto de reformas e intensa circulación de actores, instrumentos y saberes es que la administración de Martín Rodríguez-Rivadavia borrará las dos instituciones existentes que regulaban el ejercicio y la enseñanza de la medicina. El Protomedicato de Buenos Aires agonizaba desde años atrás, de manera que su supresión fue sólo un trámite formal. En cuanto al Instituto Médico Militar, institución encargada de la enseñanza y preparación de los cursos, la fundación de la Universidad proveyó del argumento para suprimirlo. El decreto lleva fecha del 12 de septiembre de 1821 y está firmado por el Ministro de Guerra Fernández de la Cruz; la supresión de la institución significó también la de los empleos de médico y cirujano de los ejércitos (Archivo General de la Nación, Sala X, Tribunal de Medicina, leg. 6-2-2). En este sentido, es que el grupo rivadaviano instaló un proceso de modernización de la enseñanza y de la profesión médica.

En este marco, el itinerario de Manuel Moreno es un ejemplo muy interesante para comenzar a pensar en ese contexto reformista el problema del ingreso de los médicos a la vida política. Recordemos que Moreno se unió al partido popular en oposición al director Juan Martín de Pueyrredón. Expulsado en febrero de 1817 por orden de Pueyrredón, se unió con Manuel Dorrego (desterrado el año anterior) en Baltimore (Di Meglio, 2014, pp. 139-165). Allí cursó sus estudios de medicina. Así, pues, al principio Moreno no tuvo mucha suerte como político. La coyuntura de la década de 1810 lo había desterrado e invalidado de participar en la vida política (Entin, 2015). Una vez, caído el poder central, regresó a Buenos Aires en 1821.

Se opuso firmemente el gobierno de Bernardino Rivadavia, y se asoció nuevamente con Dorrego en la dirección de la oposición (Cutolo, Tomo IV, pp. 661-664). A partir de 1821 fue electo diputado por el partido federal en la Sala de Representantes, cargo que desempeñó en todas las legislaturas por reelección sucesiva, hasta el año 1826 (Di Meglio, 2005, pp. 51-80). Entonces entró a representar a la provincia Oriental en el Congreso Constituyente, en el cual perteneció al partido que sostenía la conveniencia de aceptar la forma de gobierno federal para constituir las antiguas provincias del Rio de la Plata. 
Paralelamente, a partir de construir una carrera política también lograba reinsertarse en la actividad profesional local. Revalidó su título de médico en la Universidad de Buenos Aires, aunque nunca ejerció la medicina. En 1822 fue designado director de la Biblioteca Nacional, y fue miembro y presidente de la Academia de Medicina. Fundó, junto a otros, el Departamento de Medicina de la Universidad de Buenos Aires. Desde 1823, dictó la cátedra de Química en la Universidad. Así, pues, la política que en un principio le había dado la espalda ahora le servía para abrir nuevas posibilidades. La adhesión y activa colaboración en las filas del federalismo porteño que conducía Manuel Dorrego le habían permitido estabilizar su carrera profesional (Chiaramonte, 1993, pp. 81-127; Goldman y Salvatore, 1998; Goldman, 1998, pp. 103-112 y Di Meglio, 2006). Con Dorrego como gobernador, Moreno fue nombrado ministro de Gobierno, cargo que aceptó con reticencias renunciando en 1827 (Gutiérrez, 1998, p. 559).

Podríamos indicar que el caso de Justo García Valdés ofrece un recorrido diferente al de Moreno. En este caso, su reconocimiento como médico parece que fue el factor que le permitió el ingreso a la política, y no a la inversa. Recordemos que ya al producirse las invasiones inglesas tuvo una destacada actuación. Fueron reconocidos sus servicios por Santiago de Liniers quien el 16 de octubre de 1806, lo designó primer médico del ejército. En 1816 sucedió a Gorman en el Protomedicato de Buenos Aires. Al crearse la Academia de Medicina en abril de 1822 se lo designó primer presidente, encabezando además el Tribunal de Medicina en 1825 y el Departamento de Medicina, dependiente de la Universidad de Buenos Aires. Esta carrera profesional y académica en ascenso, sumando a la construcción de vínculos constantes con distintos integrantes del grupo rivadaviano, posicionó a Justo García Valdés como una figura importante de la escena pública de aquel entonces, situación que le permitió figurar en la lista de candidatos en varios períodos siendo elegido diputado en la Sala de Representantes entre los años 1829-1835. Dentro de su actuación como legislador, se destacó en el debate de la sesión del 5 de septiembre de 1829 donde se opuso en nombre de los principios republicanos, otorgar a Rosas el título de "Restaurador de las Leyes" (Diario de Sesiones..., 5 de septiembre de 1829). El 19 de diciembre de 1833, con los diputados Diego Alcorta y Mateo Vidal, presentó un proyecto de Constitución para la provincia, rechazando los intentos "absolutistas" del partido rosista (Diario de Sesiones...19 de diciembre de 1833).

Otro médico importante que actúo en el período fue Diego Alcorta quien también tuvo un rol importante en la política parlamentaria. Fue electo diputado para la legislatura de Buenos Aires por el partido de San Isidro desde 1832 hasta 1834. Al igual que García Valdés se opuso a la reelección de Rosas. Pero a diferencia del anterior, sin que esta decisión le conlleve complicaciones. Después de 1834, Alcorta decidió alejarse de la política partidaria y dedicarse solamente a la enseñanza y al ejercicio de la medicina permitiéndole sostenerse en la cátedra hasta 1842. La profesión parece que primó en su caso frente a sus deberes y obligaciones como diputado. Sin embargo, el alejamiento de la legislatura provincial no significó que Alcorta se quedase inactivo. Según parece, Alcorta tuvo una participación en la llamada "Conspiración de Maza" en 1839, que fue a su vez sostenida por dos grupos, uno más próximo al círculo íntimo de Rosas -y fomentado por el mismo Maza, yerno del unitario Valentín Alsina-, y el otro más cercano a su persona (Puentes, 1958, p. 222). ${ }^{1}$

Diferente fue la suerte de Cosme Francisco Argerich quien fue diputado en la legislatura en 1832. Participó por el debate de la concesión de facultades extraordinarias a Rosas, oponiéndose también como Alcorta y Valdés, pero lo hizo en una forma más elocuente y enérgica (Diario de Sesiones..., 19 de diciembre de 1833). Decisión que pagó caro pues vuelto Rosas al poder en 1835, lo destituyó de todos sus cargos. En 1842 se vio obligado a marchar a Montevideo. En este caso su participación en la vida política fue una experiencia alterada sin que pudiera ejercer libremente su profesión.

Moreno, Valdés, Alcorta y Argerich nos muestran distintas modalidades de relacionamiento y diferentes carreras políticas, pero todos tienen en común un aspecto: su participación se ligó al espacio deliberativo de la Sala de Representantes. Este tipo de inserción política de los médicos a través del espacio legislativo disminuirá durante el segundo gobierno de Rosas, en donde surgirán otras formas de participación, menos representativas, para reaparecer con bastante notoriedad tras 1852 . 


\section{Diversas estrategias de inserción Política DE LOS MÉdicos DURANTE EL SEgundo ROSISMO}

De las características principales del sistema político rosista se podría destacar la continuidad del ejecutivo y la centralización del poder. Como indica Marcela Ternavasio (1999, pp. 119-141 y 2002, pp. 204-205), el gobierno rosista no desarticuló el andamiaje republicano y representativo introducido por las reformas rivadavianas (1821-1824), sino que éste fue reordenado bajo la modalidad unaminista y plebiscitaria. Asimismo, durante la segunda gobernación de Rosas se produjo una participación más activa de los sectores populares y una alta politización del conjunto social. La beligerancia permanente contra todos los intentos de oposición, sumado a las guerras entabladas con potencias extranjeras, generaron una situación de constante inestabilidad política (Myers, 1995, p. 20).

En este contexto particular se insertó la vida intelectual y académica. El proceso de politización, sumado a las guerras internas y externas a lo largo del período, tuvo un impacto significativo en la Universidad de Buenos Aires, en cuyos recintos se experimentaron una serie de divisiones y conflictos (Buchbinder, 2005, pp. 48-49). Así, pues, los médicos que se formaron en estas aulas conocieron de cerca estas circunstancias de la vida pública. En tal sentido, las vidas de los médicos que aquí analizamos se conectan con este proceso de politización de la sociedad porteña.

A partir de nuevos nombramientos que se realizaron entre 1834 y 1835 en la Universidad de Buenos se produjeron cambios en el personal docente, lo que generó ciertas tensiones al interior del cuerpo médico. Al respecto, es muy sugerente la carta que Diego Alcorta le escribe a su amigo Daniel Torres que dice:

Los médicos, como ya calcularás, han formado dos facciones: una compuesta de Fernández, Montes de Oca, Manuel García, los estudiantes todos y varios particulares que los sostienen y son particularmente Pablo Salvadores, Arana, Baldonuero, y creo que los Anchorenas y Wright. La otra la forman Rivera, Montufar, Fuentes Arguivel y particulares Irigoyen, Mansilla, la Reina Madre y la princesa Mercedes. Argerich pertenece a esta última; pero no escribe (Alcorta, 27 dic.1834).

Seguramente, el objeto inicial de esta disputa tuvo que ver con las salidas y llegadas de catedráticos designados por el gobierno. Además, debe agregarse que durante junio de 1835, se estableció el decreto de juramento de fidelidad a la causa "Nacional de la Federación" (Gobierno, 20 jun. 1835). Estos decretos buscaron generar manifestaciones obligadas de pertenencia al gobierno. De tal modo, podemos afirmar que durante el período rosista existió una fuerte presencia y control en la regulación de la vida universitaria y académica. Los tipos de vínculos sociales establecidos y la misma actividad profesional se encontraron atravesados por las lógicas de poder y los acomodamientos políticos.

Por otro lado, un reflejo de los tiempos rosistas es que a partir de 1836 existen consignadas en las tesis generalmente en sus encabezados- dedicatorias referidas a asuntos públicos, fenómeno que no se aprecia en las defendidas anteriormente. También producto de la alta politización y los decretos que exigían demostrar el acatamiento al régimen federal aparecen inscripciones en las tesis para obtener el título de doctor en

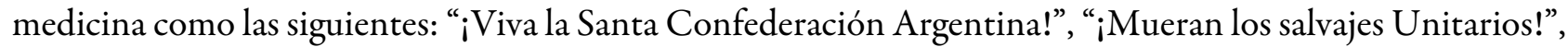
“iMuera el loco traidor salvaje unitario Urquiza!”, entre otros lemas. Pero también es cierto que conociendo el caso de Cuenca y habiendo un buen promedio de tesis, puede mitigarse la impresión que esto pueda causar, entendiendo que era algo ineludible y por tanto una simple etiqueta a seguir.

Estos problemas en conjunto tuvieron como consecuencia cierta desorganización de los estudios universitarios y la polarización de las distintas posiciones que afectó la vida personal y profesional de un número importante de médicos. En 1836 se alejaron de la enseñanza, Cosme Francisco Argerich, Juan Antonio Fernández y Juan José Montes de Oca quienes se opusieron a Rosas en distintas circunstancias, y debieron emigrar a Montevideo. En cambio, otros médicos siguieron los vaivenes de la política rosista como el doctor José María Gómez de Fonseca que siendo miembro del Tribunal de Medicina desde 1833 fue destituido por Rosas en 1835 por no considerarlo hombre de confianza de su gobierno (Fonseca se había 
opuesto a las facultades extraordinarias), pero luego, el gobernador reconsideró el caso y lo designó en 1836 profesor de Clínica Quirúrgica, cátedra que desempeñó hasta su muerte, ocurrida el 31 de noviembre de 1843 (Yrigoyen, 24 abr. 1835).

Pero también es cierto que otros médicos como el caso de Francisco Javier Muñiz muestran la contracara de aquellos que sufrieron el peso de ser opositores.

Muñiz estudió en el Instituto Médico Militar, fundado por el doctor Cosme Argerich para formar cirujanos que sirvieran al ejército. Se graduó de médico en 1822, cuando el Instituto ya formaba parte de la Universidad de Buenos Aires, creada el año anterior. Tras un corto tiempo en que figuró como cirujano militar en Carmen de Patagones, donde parece que nunca viajó, desde enero de 1825 fue cirujano de la Guardia de Chascomús. Cuando en 1826 estalló la Guerra del Brasil, fue nombrado médico y cirujano principal del Ejército, con el grado de teniente coronel. Tuvo a su cargo durante toda la campaña un importante servicio de hospitales y ambulancias, equipado con 32 carros cubiertos, y prestó especialmente servicios en la campaña que culminó en la batalla de Ituzaingó.

En 1828 regresó a Luján y fue el Administrador de la vacuna antivariólica en el partido de Luján. La aplicó a gran número de los pobladores de su jurisdicción, y salvó la vida de centenares de personas. En ese entonces, la vacuna se transmitía de brazo en brazo. Durante el segundo gobierno de Juan Manuel de Rosas fue nombrado médico de Policía, para vigilar la sanidad de la población y de sus animales - no existían los veterinarios - y controlar el ejercicio de la medicina y sancionar el curanderismo. En 1836 combatió una epidemia de escarlatina. En base a esa experiencia, en 1844 publicó en el periódico La Gaceta de Buenos Aires su Descripción y curación de la fiebre escarlatina; fue editado más tarde en un folleto de ochenta páginas (Palcos, 1943 , p. 45). Es muy probable que este haya sido su tema de tesis ya que obtuvo el doctorado en 1844 , pero no tenemos muchos datos que lo confirmen. También produjo trabajos sobre vacunas, sobre cirugía y medicina legal (Podgorny, 2010, pp. 303-352).

En 1844, la ciudad de Buenos Aires quedó desprovista de la vacuna antivariólica, debido al bloqueo anglofrancés. El gobernador Rosas pidió alguna solución a Muñiz. Éste se trasladó a Buenos Aires con una hija de pocos meses recién vacunada, con cuya linfa pudieron ser inoculadas varias personas, con lo que se pudo restablecer el circuito de vacunaciones en la ciudad.

Estando en Chascomús, en 1825, se dedicó a la observación de la naturaleza, investigando la flora y fauna locales. Siguiendo la experiencia de un sacerdote del siglo anterior, que había recogido restos de fauna extinta en las barrancas del río Luján, hizo extensas excavaciones en el mismo río. Cuando en 1828 volvió a Luján, Muñiz era ya un experto naturalista, y siguió sus investigaciones paleontológicas en su tiempo libre, extrayendo de las barrancas del río una extraordinaria serie de fósiles. Por sus propios medios, Muñiz exhumó restos de varias especies animales extinguidas, unas ya conocidas y otras descubiertas por primera vez; las reconstruyó y estudió con cuidado, comenzando así esta ciencia en el país. Entre sus hallazgos figuran mastodontes, megaterios, gliptodontes, caballos y tigres fósiles. Sus trabajos sobre Paleontología Argentina fueron compilados por Domingo Faustino Sarmiento en 1885 (Podgorny, 2007, pp.125-157).

En 1833 el naturalista británico Charles Darwin pasó por Luján en su viaje por la América del Sur; y, aunque Muñiz residía en Luján, no se conocieron personalmente. Sin embargo, más tarde, Darwin le envió desde Gran Bretaña un cuestionario sobre la variedad bovina llamada vaca ñata, relativamente frecuente en el territorio ocupado por los indígenas pampas. En base a sus muy detalladas respuestas, estableció un vínculo epistolar importante con el científico inglés. Tan es así, que sus respuestas fueron utilizadas en la segunda edición del libro El Viaje, y en el Origen de las especies de 1859 (Novoa y Levine, 2010).

En 1841 le regaló su colección paleontológica al general Rosas: once cajones acompañados por una nómina de los fósiles (Florentino Ameghino diría más tarde que no se las regaló, que en realidad el gobernador lo obligó a donarlas). Rosas no las valoró en su significado, y se las obsequió al almirante francés Dupotet. Muñiz siguió trabajando y reunió una colección de fósiles más grande aún, que donó en 1857 al museo de Buenos Aires (Pogdorny y Lopes, 2008). A fines de 1848 decidió regresar definitivamente a Buenos Aires tras veinte 
años de trabajo en Luján. Fue el médico personal de Rosas, a quien trataba por una afección prostática, y fue nombrado conjuez del Tribunal de Medicina. En la batalla de Caseros figuró como asistente del cirujano jefe del ejército rosista, junto al doctor Claudio Mamerto Cuenca, y se encargó del envío del material médico necesario para la asistencia de los heridos.

Tras el cúmulo de estas experiencias profesionales recogidas y también por la cercanía respecto al poder rosista, entendemos mejor el hecho de que en 1853, Muñiz haya sido electo diputado del Estado de Buenos Aires, por la sección de la campaña que comprendía Luján; y, al año siguiente, senador provincial. ${ }^{2}$ No decimos que éstas hayan sido los "desencadenantes" pero sí que seguramente fueron significativas para la iniciación de Muñiz en cargos más relevantes. Pero no solo crecieron políticamente los que estuvieron cercanos a la política rosista.

Otro caso interesante es el del médico y poeta Claudio Mamerto Cuenca. Ante la inflexibilidad que imponía el sistema rosista, Cuenca optó por una estrategia de simulación o de enmascaramiento entre lo que pensó políticamente y lo que hizo profesionalmente. Hijo de Don Justo Casimiro Cuenca y de Doña Lucía Calvo, nace el 3 de octubre de 1812. Hizo sus primeras letras en la casa parroquial para ingresar a los 16 años en el Colegio San Carlos. Se recibió de Bachiller con notas sobresalientes y cuatro años más tarde ingresaba al Departamento Médico de la Universidad de Buenos Aires. Junto a su hermano, Salustiano, lograban también sobresalir en los estudios superiores. ${ }^{3}$ En el año 1838 comenzó Claudio Mamerto Cuenca su actuación como profesional y cinco años más tarde se lo designa como profesor de Anatomía, desarrollando una carrera profesional y docente que lo impulsa a colocarse, ante la vacante que se produce con el viaje a Europa del doctor Ventura Bosch, médico personal de Juan Manuel de Rosas y de su tropa, en una terna conjuntamente con el doctor Juan José Montes de Oca y con un médico francés de apellido Solier, de mucho prestigio, y era elegido para reemplazar a aquél en las funciones que cumplía como médico privado de Rosas y del ejército federal. ${ }^{4}$

La vida de Cuenca transcurrió muy cercana al poder; pero nada dejaba percibir el drama oculto que lo atormentaba de tener que formar parte de los hombres de Rosas y en su intimidad se desahogaba con su fecunda producción literaria, producción que mantuvo oculta. La mayoría de sus conocidos emigraban a Montevideo, pero Cuenca prefirió quedarse haciendo uso de la simulación. El cumplimiento del deber lo obligó a servir a Rosas y a sus tropas pero en la intimidad, Cuenca escribía los siguientes versos:

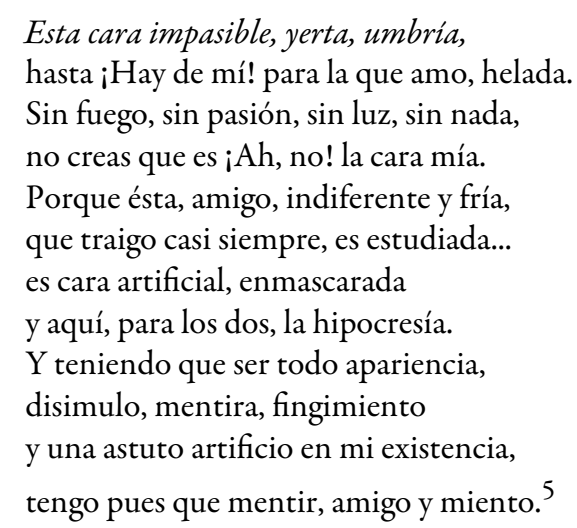

En la interrelación que se podía establecer entre la política y el mundo académico, esta era otra modalidad de ejercer la profesión. O para decirlo, en otras palabras, era el estado anímico de los médicos y hombres ligados al conocimiento que optaron por no abandonar Buenos Aires. Convertido en médico personal y cirujano mayor del ejército de Rosas, volcando en sus poemas sus verdaderos sentimientos, Cuenca encontró la muerte el 3 de febrero de 1852. 


\section{EL RETORNO AL ESPACIO DELIBERATIVO Y EL INGRESO AL EJECUTIVO}

Varios de los médicos, formados profesionalmente en la etapa rosista, luego ejercieron cargos claves en la década de 1850 tales como Francisco Javier Muñiz, Mauricio González Catán, Pedro Ventura Bosch, Guillermo Rawson y Juan José Montes de Oca. Claro está que las circunstancias políticas y económicas habían cambiado. Rosas había caído tras la batalla de Caseros en 1852 y con ello se abría un escenario de diez años de conflictos entre Buenos Aires y la Confederación por el liderazgo y por la aplicación de diversos proyectos de nación en la reconstrucción del orden político (Scobie, 1977; Halperin Donghi, 1995; Sabato, 1998; Lettieri, 1998 y Bragoni y Míguez, 2010).

Pedro Ventura Bosch nació en Buenos Aires, el 14 de julio de en 1814. Realizó en esta ciudad sus estudios preparatorios e ingresó luego a la Facultad de Medicina, donde se graduó en 1835. Al año siguiente, obtuvo el doctorado con su Tesis sobre el Cáncer uterino. Desde 1834, fue practicante en el Hospital General de Hombres, y colaboró con la Cátedra de Nosografía y Clínica Quirúrgica, que dirigiría a partir de 1843 . A fines de la década de 1840, Bosch era ya un médico reconocido, que atendía a lo más selecto de la sociedad porteña en su consultorio particular, al tiempo que era visitado por numerosos indigentes y por personas de escasos recursos, a las que atendía gratuitamente (Cutolo, Tomo I, p. 510). Unos años después, a pesar de simpatizar con el bando unitario, fue también el médico de confianza de Rosas. En 1851 viajó a Europa, y regresó con la caída del rosismo, un año después. Entonces, pasó a comandar la Comisión de Filantropía e Higiene, que dirigía todos los hospitales de la ciudad. En esa función, consiguió que en 1853 el Gobernador Obligado cediera el antiguo edificio de la Convalecencia, ubicado en las afueras de la ciudad, para la instalación del Hospital para Mujeres (luego "Hospital Nacional de Alienadas" y actualmente "Hospital Braulio Moyano"), que fue habilitado en 1854. En 1852 fue elegido diputado en la Cámara, como Senador dos años después, y en períodos sucesivos, siendo presidente de la corporación municipal. Bosch representaría un modelo de acceso al poder mediante el prestigio de su profesión y sus capacidades técnicas. De hecho, como legislador, se preocupó en especial por hacer medidas relativas a su actividad. En 1857, otra idea suya se hizo realidad: el Hospicio de Hombres, que se llamó, luego de 1863 y en su homenaje, "Hospicio de San Buenaventura" (luego se denominó "Hospicio de las Mercedes" y actualmente se llama "Hospital José T. Borda"). Este itinerario de vida, sin dejar de lado las singularidades y las variaciones, se reproduce en otros casos lo que evidentemente demuestra una presencia importante de médicos en los resortes del poder político en 1850.

También avanzaron los que se habían ampararon en el federalismo urquicista como es caso de Mauricio González Catán quién nació en Buenos Aires el 22 de septiembre de 1823 . Hizo sus primeros estudios en la parroquia de Monserrat, y en 1836 pasó al colegio de los franciscanos. Ingresó a la facultad de Medicina en 1839, y alcanzó en 1845, el diploma de profesor de cirugía y partos, cuando solo tenía 22 años. Fue practicante de vacuna, y al preparar su examen general para optar al doctorado hizo renuncia de dicho cargo que era gratuito, lo que no solo no le fue aceptada, sino que, presentándose en Administrador de Vacuna en queja al gobernador Rosas contra él y otros practicantes que habían procedido de igual manera, el gobierno los consideró salvajes unitarios y los tuvo presos durante 19 días. Se gradúo de doctor en medicina y cirugía el 20 de noviembre de 1848. Apadrinado por su maestro, el doctor Claudio Mamerto Cuenca, presentó su tesis titulado Disertación sobre la Coqueluche. Paso luego a Entre Ríos prestar servicios en calidad de cirujano del ejército de Urquiza en 1846. Acompañó a Urquiza en la batalla de Caseros y se encontró en ella con quien había sido su maestro el doctor Cuenca que formada parte de la guardia de Rosas. De regreso a Buenos Aires, se dedicó a su profesión siendo nombrado profesor de obstetricia en la Facultad de Medicina. Fue miembro de la municipalidad y legislador provincial en 1868 y presidente de ese cuerpo. Luego fue senador 1877 y diputado nacional en 1888 (Gutiérrez Vicente, 1969).

En cuanto a Juan José Montes de Oca, el rosismo actúo como un factor de expulsión profesional. Por sus "peligrosas amistades unitarias", fue separado de su cátedra en la Universidad, y se vio forzado a emigrar a la isla de Santa Catalina, en Brasil, donde ejerció su profesión hasta trasladarse a Río de Janeiro. En Río 
de Janeiro adquirió rápidamente prestigio como cirujano y se desempeñó eficazmente en la lucha contra la epidemia de fiebre amarilla que azotó la ciudad desde 1849. Montes de Oca regresó a Buenos Aires tras la caída de Rosas. En 1858 fue quien lanzó la primera alarma de la llegada a Buenos Aires de la primera invasión de fiebre amarilla. En 1862 asumió la Presidencia de la Facultad de Medicina de la Universidad de Buenos Aires. Durante la Guerra de la Triple Alianza marchó con el ejército al Paraguay. Durante catorce años ejerció funciones legislativas en la Cámara de Diputados y en el Senado de la Provincia de Buenos Aires, institución que llegó a presidir. ${ }^{6}$

Por último podemos analizar la trayectoria de Guillermo Rawson la cual puede interpretarse como una forma de acceso al poder construida desde la política provincial para luego pasar a la política nacional. En 1844, Rawson, tras concluir sus estudios universitarios, regresó a su provincia natal -San Juan-, donde comenzó a ejercer su profesión. Allí, se desempeñó como el médico de las principales familias, incluso la del gobernador Benavídez, quien le dio un trato especial. La provincia estaba gobernada por Nazario Benavídez, un caudillo federal, fiel seguidor de Rosas.

Rawson se había propuesto, junto a Juan Francisco Seguí, provocar un levantamiento en contra de Rosas; sin embargo, no coincidían en quien debía hacerlo: mientras Seguí creía que el indicado era Justo José de Urquiza, gobernador de Entre Ríos, Rawson sostenía que sería más simple convencer a Benavídez.

En dichas circunstancias, Rawson accedió a la cámara en 1844, ya que fue incluido en la lista el mismo día de la elección por un grupo de amigos; posteriormente, fue reelecto en el cargo, esta vez junto a su amigo Tadeo Rojo. Convencido de que ningún despotismo podía enfrentarse a pobladores educados, Rawson y Rojo impulsaron la sanción de una ley de educación primaria para la instrucción de los ciudadanos, la cual fue vista con agrado por Benavídez; también promovieron una ley que amparaba la creación de municipalidades rurales. A pesar de su disconformidad, Benavídez continuó dejándolos hacer, aunque comenzaron a ser vistos como opositores (Maurin Navarro, 1972, p. 17).

En 1851, Rosas le ordenó a los gobernadores federales que le entregasen el título de Jefe Supremo de la Confederación, además de la suma del poder público y el ejercicio de su suprema autoridad, con el objetivo de evitar el pronunciamiento de Justo José de Urquiza y su alianza con el Imperio del Brasil y el Uruguay. Antes de enviar el proyecto a la Legislatura, Benavídez se reunió en su hogar con ciertos ciudadanos para aconsejarse; entre ellos estaba Rawson, quien le solicitó que rechazase el pedido de Rosas. Sin embargo, a pesar del entusiasmo de Rawson, Benavídez no creía contar con el poder suficiente para enfrentarse al Restaurador y consideraba que el único capaz de realizar dicha acción era Urquiza; por su parte, Rawson mantenía correspondencia con Sarmiento. Con este marco, Benavídez envió el proyecto a la Legislatura, que se reunió inmediatamente para tratar el asunto.

Rawson anunció que hablaría en la Legislatura, oponiéndose a las pretensiones rosistas, lo que hizo que muchas personas presenciaran aquella sesión. Todos los diputados avalaron el proyecto, excepto Rawson, quien se opuso fervientemente y pronunció una arenga, en la que pedía que se rechazase la petición de Rosas (Maurin Navarro, p. 24). Al conocerse la noticia del levantamiento de Urquiza, Rawson reunió en su hogar a un grupo de amigos con el objetivo de firmar una petición, en la cual solicitaron a Benavídez que adhiriera al pronunciamiento del caudillo entrerriano; sin embargo, un grupo partidario de Rosas rodeó la casa y los obligó a dispersarse.

El 3 de febrero de 1852 Rosas fue derrotado por Urquiza en la batalla de Caseros; el 28 de ese mismo mes, un escribano de gobierno anunció el hecho en San Juan. A pesar de la caída de Rosas, Benavídez se mantuvo en el gobierno por algunos años más; en un intento por reorganizar el país, Urquiza convocó a los representantes de las provincias a la Conferencia de San Nicolás, de la cual surgió el acuerdo; Benavídez asistió y quiso que Rawson lo acompañase, pero este se rehusó.

Con el gobernador fuera de la provincia se produjo el levantamiento de la Legislatura, que destituyó a Benavídez y lo reemplazó por un gobierno provisorio, a cargo del comerciante salteño Zacarías Yanzi; sin embargo, Urquiza ordena la invasión de la provincia, las autoridades revolucionarias son depuestas y 
Benavídez vuelve a ocupar su cargo. Rawson es mandado a perseguir y es encarcelado, siendo encerrado en la cárcel de San Clemente.

Rawson posteriormente fue diputado por San Juan en el Congreso de Paraná en 1855. Tras la derrota militar de Urquiza en la batalla de Pavón, los políticos porteños le ofrecieron una banca como Senador provincial. En 1862, San Juan le ofrece la de Senador Nacional y, ese mismo año, durante la presidencia de Bartolomé Mitre, será nombrado Ministro del Interior. Quizás el caso de Rawson sea el más emblemático de un verdadero cursus honorum en la carrera política además de ser el primero de los médicos que además de tareas legislativas ocupó y ejerció un cargo en el poder ejecutivo nacional. Desde este lugar, propiciará la creación de la Cruz Roja y todo tipo de medidas higienistas (González Leandri, 1999, pp.57-110).

\section{CONCLUSIONES. LAS HUELLAS EN EL PODER}

Manuel Moreno, Diego Alcorta, García Valdés, Cosme Francisco Argerich, Francisco Javier Muñiz, Claudio Mamerto Cuenca, Mauricio González Catán, Pedro Ventura Bosch, Juan José Montes de Oca y Guillermo Rawson representaron distintas modalidades de acceso al poder político. Estas intervenciones se fueron escalonando durante las primeras décadas de 1850 y 1860 . A la lista se podrían sumar Carlos Gustavo Durand, quien cumplió los cargos de diputado provincial por la campaña de Buenos Aires en 1859 y senador por la provincia de Buenos Aires entre 1865-1870 y, posteriormente, Eduardo Wilde quien fue diputado provincial y nacional adhiriendo al Partido Autonomista Nacional y luego será Ministro de Justicia y Educación durante la primera Presidencia de Julio Argentino Roca.

Cabe mencionar pues que durante la etapa rosista, algunos médicos lograron experimentar y hacer política a partir de las posibilidades que les ofreció el sistema político de ese entonces. Otros médicos, en cambio, fueron imposibilitados de este ejercicio pero igualmente quedaron marcados por esas experiencias a tal punto que, posteriormente, no dudaron en acercarse y participar en la construcción política tras la caída de Rosas. La politización del régimen rosista produjo variadas reacciones de los médicos: desde el acompañamiento, la simulación, la oposición explicita, la oposición silenciosa o clandestina, los exilios, etc.

En este itinerario podríamos identificar tres momentos clave. En la década de 1820 y los primeros años de la siguiente, se advierte una presencia de médicos que acceden a la práctica política en el marco del poder legislativo provincial. En esta etapa varios médicos fueron elegidos diputados de la Sala de Representantes de Buenos Aires participando en importantes debates parlamentarios. Posteriormente, a partir del segundo gobierno de Rosas, si bien se produce un alejamiento de los médicos del espacio deliberativo, éstos no dejaron de estar ausentes desarrollando otras estrategias de intervención política, por cierto, más informales. Estas modalidades de participación fueron variadas, y dependiendo de los casos, iban desde generar habilidades para estrechar acercamientos y vínculos con los "hombres de poder", re-posicionarse a partir del crédito profesional y/o en su prestigio científico adquirido; en caso de no adherir con la propuesta de Rosas, montar maniobras de simulación, declararse en oposición abierta y participar en levantamientos militares, optar por acciones de índole más silenciosa o clandestina y/o, ocuparse de ejercer duras críticas y formar alianzas desde el exilio. Luego de 1852 y en adelante, encontramos una etapa en donde los médicos que actuaron en el período anterior se lanzaron a participar de la política pero esta vez (otra vez) mediante los cuerpos legislativos e incluso alcanzando cargos en el Ejecutivo nacional.

El escenario político iba generando el paulatino fenómeno de incluir a los médicos como componentes de los poderes del Estado provincial y posteriormente nacional. La particularidad fue que en general comenzaron en los cuerpos legislativos colegiados. Esto supuso el aprendizaje de una serie de convenciones, reglas institucionales y estrategias desconocidas que produjo la incorporación de una experiencia política e a la hora de argumentar, discutir y ponerse de acuerdo para votar las leyes.

Ahora bien, este fenómeno prematuro nos sugiere que habría que repensar el problema de los orígenes del llamado higienismo y la inserción de los médicos dentro del Estado nacional ubicado hacia 1880 para el caso 
Argentino. Es cierto que la posición de los médicos como expertos-técnicos (José María Ramos Mejía, José Ingenieros, Alejandro Korn, José Penna, Emilio Coni, entre otros), la implementación de políticas públicas en materia de salud, y la supremacía discursiva de la voz higiene, fueron elementos que convergieron entre 1880 y 1930 . Para ese entonces, el discurso de la higiene pública y la higiene mental, se vio ligado a la aparición de la "cuestión social" que penetró y se extendió a los sistemas educativos, a la infancia, a la vida familiar, al deporte, al trabajo, a la alimentación, al mejoramiento del espacio urbano, a las políticas de estado (Kohn Loncarica, 1992; Vallejo, 1996; Sánchez, 2007 y Di Liscia y Salto, 2004).

Todos los recursos fueron útiles para crear hábitos saludables, fueran formales o informales, pensados para las poblaciones urbanas, residentes en los conventillos o inquilinatos, donde el cólera, la fiebre amarilla, la tuberculosis, las enfermedades venéreas, la desnutrición materno-infantil y algunas otras dolencias, se ensañaban con la población. En este marco, actuaron entidades como el Departamento Nacional de Higiene, la Asistencia Pública y el Patronato de la Infancia, a las que se sumaron muchas otras asociaciones, donde no faltaron las de beneficencia y las de socorros mutuos. Médicos, maestros, visitadoras, asistentes sociales, diversos profesionales más la labor de los políticos, se congregaron con determinación para resolver estos problemas. En efecto, la epidemia de 1871 sacudió y transformó la vida social e institucional de Buenos Aires con enorme dramatismo. Al respecto, Diego Armus (2005) indica que la epidemia de 1871 se recordó en la memoria colectiva de la ciudad como un parteaguas simbólico: la gran aldea y sus recurrentes azotes epidémicos debían quedar atrás si se quería construir una ciudad y una nación modernas.

No deseamos caer en un enfoque teleológico sino proponer una mirada más compleja y profunda para las explicaciones sobre el tema. Los nombramientos de médicos en la gestión política se hicieron repetitivos, y también se hizo de la higiene un tema recurrente para los años posteriores a 1880 porque, además de la búsqueda de modernización y el ordenamiento de "la cuestión social", existieron factores anteriores que lo permitieron, no directamente causales pero sí desplegados con anterioridad.

En nuestra perspectiva hay que señalar que existieron elementos y procesos previos que posibilitaron ese predominio posterior de lo médico (en los actores, en las instituciones, en los saberes y prácticas) y que no han sido profundizados en toda su dimensión. Como se ha tratado de demostrar, el acceso a la participación política de diversa índole suministraría cierta acumulación de experiencias en el manejo de poder político y, en especial, en el espacio deliberativo. Los médicos, como grupo profesional, lograron acumular saber-poder en las fronteras de una dirigencia política en formación -incluso con más alcance que respecto de la sociedad-, hasta hacerse inteligibles y familiares en el entramado estatal.

\section{FUENTES DOCUMENTALES}

Archivo General de la Nación, Sala X, Tribunal de Medicina, legajo 6-6-2 y 6-6-2A.

Gobierno de la Provincia de Buenos Aires. Decreto. Fórmula de todo juramento que se debe prestar públicamente, de 20 de junio de 1835. En: De Angelis, Pedro. Recopilación de leyes y decretos promulgados en Buenos Aires desde el 25 de mayo de 1810 hasta el fin de Diciembre de 1835. Buenos Aires: Imprenta del Estado. v.2, p.1283. 1836.

Alcorta, Diego. Carta a Daniel Torres. 27 diciembre de 1834. En: Archivo General de la Nación, Argentina, Sala VII, Documentación de Daniel Torres, leg. 1943.

Yrigoyen, Manuel. Comunicación del Ministerio de Gobierno al Ministerio de Hacienda. 24 abril de 1835. En: Archivo General de la Nación, Sala X, Tribunal de Medicina, leg. 6-6-2A.

Diario de Sesiones de la Junta de Representantes de la Provincia de Buenos Aires, 5 de septiembre de 1829, Nro. 179, Tomo 9, Buenos Aires, Imprenta de la Independencia. En: Biblioteca Nacional, Sala del Tesoro, ref. 05-5-6-25. 
Diario de Sesiones de la Junta de Representantes de la Provincia de Buenos Aires, 19 de diciembre de 1833, Nro. 370, Tomo 17, Buenos Aires, Imprenta de la Independencia. En: Biblioteca Nacional, Sala del Tesoro, ref. 05-5-7-03.

\section{REFERENCIAS}

Armus, D. (2005). El descubrimiento de la enfermedad como problema social. En Mirta Lobato (dir.), Nueva Historia Argentina, Tomo V: El progreso, la modernización y sus límites (1880-1916) (pp. 507-551). Buenos Aires: Sudamericana.

Asúa, M. de. (2010). La ciencia de mayo. La cultura cientifica en el Río de la Plata, 1800-1820. Buenos Aires: FCE.

Bragoni, B. y Míguez, E. (coords). (2010). Un nuevo orden politico. Provincias y Estado Nacional 1852-1880. Buenos Aires: Biblos.

Buchbinder, P. (1997). Historia de la facultad de filosofía y letras. Buenos Aires: Eudeba.

Chiaramonte, J. C. (1993). El federalismo argentino en la primera mitad del siglo XIX. En M. Carmagnani, (coord.), Federalismos Latinoamericanos: México/Brasil/Argentina (pp. 81-127). México D.F: F.C.E.

Cutolo, V. (1958-1985). Nuevo Diccionario biográfico argentino: 1750-1930. Buenos Aires: Elche.

Di Liscia, M. S. (2002). Saberes, terapias y prácticas médicas en Argentina (1750-1910). Madrid: CSIC.

Di Liscia, M. S. y Salto, G.S. (2004). Higienismo, educación y discurso en la Argentina (1870-1940). Santa Rosa: Universidad Nacional de La Pampa.

Di Meglio, G. (2005). Manuel Dorrego y los descamisados. La construcción de un líder popular urbano en la Buenos Aires posrevolucionaria. Estudios Sociales, 29, 51-80.

Di Meglio, G. (2006). ¡Viva el bajo pueblo! La plebe urbana de Buenos Aires y la politica entre la revolución de mayo y el rosismo. Buenos Aires: Prometeo.

Di Meglio, G. (2014). Manuel Dorrego. Vida y muerte de un lider popular. Buenos Aires: Edhasa.

Di Pasquale, M. y Summo, M. (comps.). (2015)Trayectorias singulares, voces plurales. Intelectuales en la Argentina, siglos $X I X-X X$. Sáenz Peña: EdUntref.

Entin, G. (2015). Los desterrados de la república. Revolucionarios del Río de la Plata en los Estados Unidos (1816-1817). En J. Moisand; J.L. Simal, et al (comps.), Exils entre les deux mondes. Migrations et espaces politiques atlantiques au XIXe siècle. Rennes: Les Perséides.

Fitoussi, J.-P. y Rosanvallon, P. (1997). La nueva era de las desigualdades. Buenos Aires: Manantial.

Goldman, N. (1998). Los orígenes del federalismo rioplatense (1820-1831). En N. Goldman, (dir.), Revolución, República, Confederación (1806-1852), Nueva Historia Argentina, Tomo III (pp. 103-124). Buenos Aires: Sudamericana.

Goldman, N. (2000). Libertad de imprenta, opinión pública y debate constitucional en el Río de la Plata (1810-1827). Prismas, Revista de Historia Intelectual, 4, 9-20.

Goldman, N. (2003). Formas de gobierno y opinión pública o la disputa por la acepción de las palabras, 1810-1827. En H. Sabato y A. Lettieri, (comps.), La vida politica en la Argentina del siglo XIX. Armas, votos y voces. Buenos Aires: F.C.E.

Goldman, N. y R. Salvatore (eds.). (1998). Caudillos rioplatenses. Nuevas miradas a un viejo problema. Buenos Aires: Eudeba.

González Leandri, R. (1999). Curar, persuadir, gobernar. La construcción histórica de la profesión médica en Buenos Aires (1852-1886). Madrid: CSIC.

González Leandri, R. (2005). Madurez y poder. Médicos e Instituciones sanitarias en Argentina a fines del siglo XIX. Entrepasados, Revista de Historia, XIV(27), 133-150.

González Leandri, R. (2006). Campos e imaginarios profesionales en América Latina. Anuario IEHS, 331-344. 
Gutiérrez, J. M. (1998). Noticias históricas sobre el origen y desarrollo de la enseñanza pública superior en Buenos Aires 1868. Quilmes: Universidad Nacional de Quilmes.

Gutiérrez, V. (1969). Mauricio González Catán, Primer profesor de Anatomia Topográfica en la Escuela de Medicina de Buenos Aires. Buenos Aires: Academia Nacional de Medicina.

Halperin Donghi, T. (1995). Proyecto y construcción de una nación, 1846-1880. Buenos Aires: Ariel.

Kohn Loncarica, A. (1992). Ciencia y Estado en la Argentina. Una perspectiva histórica de sus relaciones. Buenos Aires: Universidad de Buenos Aires.

Lettieri, A. (1998). La república de la opinión. Política y opinión pública en Buenos Aires entre 1852 y 1862. Buenos Aires: Paidós.

Maurin Navarro, E. (1972). Tres maestros de la medicina argentina. San Juan: Academia Provincial de la Historia.

Myers, J. (1998). La revolución en las ideas: la generación romántica de 1837 en la cultura y políticas argentinas. En N. Goldman, (dir.), Nueva Historia Argentina, Tomo III: Revolución, República, Confederación (1806-1852) (pp. 383-443). Buenos Aires: Sudamericana.

Myers, J. (1995). Orden y virtud. El discurso republicano en el régimen rosista. Bernal: Universidad Nacional de Quilmes.

Novoa, A. y Levine, A. (2010). From Man to Ape. Darwinism in Argentina, 1870-1920. Chicago: Chicago University Press.

Palcos, A. (1943). Nuestra ciencia y Francisco Javier Muñiz. El sabio. El héroe. La Plata: Universidad Nacional de La Plata.

Podgorny, I. (2007). De ángeles, gigantes y megaterios. Saber, dinero y honor en el intercambio de fósiles en las provincias del Plata en la primera mitad del siglo XIX. En R. Salvatore (ed.), Los lugares del saber. Contextos locales y redes transnacionales en la formación del conocimiento moderno (pp. 125-157). Rosario: Beatriz Viterbo.

Podgorny, I. (2010). Los médicos de muertos y la paleontología en la Plata. Medicina legal, cirugía militar y observación de campo en la obra de Francisco X. Muñiz, 1830-50. Anuario IEHS, 25, 303-352.

Pogdorny, I. y Lopes, M. M. (2008). El desierto en una vitrina. Museos e historia natural en la Argentina. México D.F.: Limusa.

Puentes, G. (1958). La intervención francesa en el Río de la Plata. Federales, unitarios y románticos. Buenos Aires: Ediciones Teoría.

Sabato, H. (1998). La politica en las calles. Entre el voto y la movilización. Buenos Aires, 1862-1880. Buenos Aires: Sudamericana.

Sánchez, N. I. (2007). La higiene y los higienistas en la Argentina (1880-1943). Buenos Aires: Sociedad Científica Argentina.

Scobie, J. (1977). La luch a por la consolidación de la nacionalidad argentina, 1852-1862. Buenos Aires: Hachette.

Ternavasio, M. (2002). La revolución del voto. Politica y elecciones en Buenos Aires, 1810-1852. Buenos Aires: Siglo XXI.

Ternavasio, M. (1998). Las reformas rivadavianas en Buenos Aires y el Congreso General Constituyente. En N. Goldman, (dir.), Nueva Historia Argentina, Tomo III:Revolución, República, Confederación (1806-1852) (pp. 161-197). Buenos Aires: Sudamericana.

Ternavasio, M. (1999). Hacia un régimen de unanimidad: política y elecciones en Buenos Aires, 1828-1850. En H. Sabato (ed.), Ciudadanía politica y formación de las naciones (pp. 119-141). México: Fondo de Cultura Económica.

Vallejo, G. (1996). Escenarios de la cultura cientifica Argentina: ciudad y universidad (1882-1955). Madrid: CSIC.

\section{Notas}

1 En el primer grupo, destacan: Maza, Enrique Lafuente, Jacinto Rodríguez Peña, Carlos Tejedor, Santiago Rufino Albarracín y Rafael Jorge Corvalán, también Dominga Buchardo de Balcarce, Ambrosio Ayllones, Saturnino Soriano, Francisco Posas, Carlos Atkinson, Juan Chassaing y Antonio López. Por el grupo de Alcorta, estaban Juan Thompson, Avelino González Balcarce y los unitarios Valentín San Martín, Valentín Gómez, y también Gervasio Rosas, Corvalán, 
Hilario Lagos, Mariano Lozano, Diego Arana, Manuel, Guillermo Pinto y Félix de Álzaga, y se comunicaban con Lavalle por medio de Félix Frías.

2 Desde 1858 hasta 1862, fue presidente de la Facultad de Medicina de la Universidad de Buenos Aires. Prestó servicios militares como cirujano del ejército de Buenos Aires en la batalla de Cepeda, y también fue cirujano jefe de los campamentos argentinos en la Guerra del Paraguay. Durante la epidemia de fiebre amarilla de 1871, fue uno de los médicos voluntarios para ayudar a las víctimas, pero terminó por ser él mismo una de ellas. Murió en abril de 1871 en Buenos Aires, víctima de la fiebre amarilla.

3 Salustiano Cuenca se transforma en cirujano, sucediendo a su hermano en la Cátedra de Anatomía y Fisiología y muere durante la epidemia de cólera en el año 1859.

4 Vicente Osvaldo Cutolo, Nuevo Diccionario..., op. cit., Tomo II, p. 416.

5 Claudio Mamerto Cuenca, "Mi Cara, soneto", en Claudio Mamerto Cuenca, Obras poéticas, Tomo III, Buenos Aires, El Nacional, 1861, p. 73.

6 Juan José Montes de Oca murió víctima del agravamiento de una afección bronquio-pulmonar en Buenos Aires el 22 de febrero de 1876, poco antes de cumplir 70 años. 